\title{
A SLIP-LINE FIELD FOR PLOUGHING DURING ORTHOGONAL CUTTING
}

\author{
Daniel J. Waldorf ${ }^{1}$, Richard E. DeVor ${ }^{2}$, Shiv G. Kapoor ${ }^{2}$ \\ ${ }^{1}$ ATF, Inc. \\ Quality Department \\ 3550 W. Pratt Avenue \\ Chicago, IL 60645 \\ 2Mechanical and Industrial Engineering Department \\ University of Illinois at Urbana-Champaign \\ Urbana, IL 61801
}

\begin{abstract}
Under normal machining conditions, the cutting forces are primarily due to the bulk shearing of the workpiece material in a narrow zone called the shear zone. However, under finishing conditions, when the uncut chip thickness is of the order of the cutting edge radius, a ploughing component of the forces becomes significant as compared to the shear forces. Predicting forces under these conditions requires an estimate of ploughing. A slip-line field is developed to model the ploughing components of the cutting force. The field is based on other slip-line fields developed for a rigid wedge sliding on a half-space and for negative rake angle orthogonal cutting. It incorporates the observed phenomena of a small stable build-up of material adhered to the edge and a raised prow of material formed ahead of the edge. The model shows how ploughing forces are related to cutter edge radius - a larger edge causing larger ploughing forces. A series of experiments were run on 6061-T6 aluminum using tools with different edge radii - including some exaggerated in size - and different levels of uncut chip thickness. Resulting force measurements match well to predictions using the proposed slip-line field. The results show great promise for understanding and quantifying the effects of edge radius and worn tool on cutting forces.
\end{abstract}

\section{INTRODUCTION}

The first studies on the phenomenon of ploughing in metal cutting (Albrecht 1960) were undertaken in an attempt to explain why the apparent coefficient of friction between the rake face of the tool and the chip varied with rake angle. A finite radius on the cutting edge was believed to be responsible by contributing additional forces as some material was directed downward below the edge and pressed into the workpiece. Although the discovery of a secondary shear zone at the tool-chip interface changed the view of friction at that interface, ploughing and its importance in cutting became the subject of a number of investigations (Palmer and Yeo, 1963; Johnson, 1967; Moneim and Scrutton, 1974; Heginbotham and Gogia, 1961) and continue to be studied (Rubenstein, 1990; Zhang et al., 1991; Sawar and Thompson, 1981; Parthimos et al., 1993; Wu, 1988; Endres et al., 1995; Elanayar and Shin, 1994) as researchers attempt to gain a complete understanding of the mechanisms of the cutting process. For example, a size effect on cutting forces has long been observed, in which the ratio of forces to the area of cut increases as uncut chip thickness decreases. While this effect can be explained in part by a varying shear angle, ploughing is also believed to play a role. Wu (Wu, 1988) and others (Endres, et al., 1995; Elbestawi, et al., 1991; Sisson and Kegg, 1969; Albrecht, 1965) believe that because of its phase lag with respect to uncut chip thickness variation due to dynamic vibrations, the ploughing component of cutting forces is directly related to cutting process damping and machine-tool stability issues. Since the ploughed material eventually becomes a part of the machined workpiece surface, understanding the phenomenon of ploughing has been linked (Johnson, 1967; Haslam and Rubenstein, 1970; Thomsen, et al., 1953) to the study of the properties of the machined surface. Furthermore, the indenting nature of the ploughing process bears resemblance to the contact of a worn flank surface, and many researchers (Elanayar and Shin, 1994; Usui, et al., 1984) have studied the ploughing component of forces as part of an attempt to predict forces on a worn tool.

Several physical models of the ploughing mechanism have been proposed, but very little verification of those models has taken place because of the difficulty in measuring ploughing forces and separating them from the total cutting force. Rubenstein and others (Rubenstein, 1990; Haslam and Rubenstein, 1970; Connolly and Rubenstein, 1968) describe an extrusion-recovery mechanism in which a thin layer of material initially at a depth $\mathrm{h}$ (see Figure 1) above the level of the bottom of the cutting edge is extruded below the edge and recovers back to its original level. The material is thought to have a separation 
point $\mathrm{S}$ on the cutting edge at a critical rake angle as, estimated to be around 70 $\square$. Others (Wu, 1988; Endres et al., 1995; Sisson and Kegg, 1969) have taken a similar view, suggesting empirical calibration of the penetration depth $\mathrm{h}$ and predicting ploughing forces proportional to the elastically displaced volume of the extruded material. Elanayar and Shin (Elanayar and Shin, 1994) also propose an empirical fit to $\mathrm{h}$ and model the mechanism as elastic indentation rather than extrusion. Unfortunately, little evidence has been presented to support such a description of the physical scenario at tool tip, while some evidence has been shown to contradict it (Sarwar and Thompson, 1981; Waldorf et al., 1996) . In a study using plasticity methods (Johnson, 1967)], a slip-line field was developed for restricted contact tools predicting sublayer plastic flow and even a chip exiting from the rear contact of the edge with the workpiece. This, however, has not generally been observed during orthogonal cutting. Still other models (Palmer and Yeo, 1963; Moneim and Scrutton, 1974; Zhang et al., 1991; Sarwar and Thompson, 1981) predict plastic flow beneath the edge and postulate a stable build-up of material adhered to the edge. Each of these theories/models has used plasticity methods and slip-line fields to model the flow, but the experimental difficulties of isolating the ploughing force components has resulted in very little verification of the models. Consequently, no consensus exists as to a reasonable method for predicting the ploughing forces or for decomposing a measured force into shearing and ploughing components.

This paper presents a new slip-line model of the ploughing process in orthogonal cutting. The model is based on the assumption of a stable build-up adhered to the finite radius cutting edge. Instead of material separating at a stagnation point on the edge, the flow is diverted at the extreme edge of the build-up. Experimental results are compared to the theoretical predictions to show the success of the model. It is anticipated that the model will serve as a starting point for the development of a predictive algorithm for ploughing forces allowing for simple decomposition of measured forces into components due to shearing and ploughing.

\section{THE SLIP-LINE MODEL}

The ploughing process is complex because it involves both a sliding/indenting action of the tool edge on the workpiece and an interaction with the primary plastic deformation zone associated with the bulk shearing of the workpiece. As such, the proposed slip-line field representing ploughing derives partly from previous fields developed for wedge sliding and chip cutting mechanisms. Black, Kopalinsky, and Oxley (Black et al., 1993) present a review of fourteen years of research improving upon a model, originally proposed by Challen and Oxley (Challen and Oxley, 1979) and based on (Avitzur and Zhu, 1985), for asperity deformation and wedge sliding as a description of friction and wear processes. The result is a wave model for the sliding wedge (see Figure 2) in which material ahead of the wedge is compressed and pushed up to meet the wedge face, resulting in a moving wave of workpiece material ahead of the wedge. Considerable evidence has accumulated in support of the model (Black et al., 1993) [which has primarily been used to determine frictional relationships (see [Avitzur and Zhu, 1985]). The same compression of material and resulting stresses must also be present for the sliding contact of a cutting edge, except that the wave is not clearly seen since it is so small and is generally removed as part of the chip. A slip-line field proposed by Abebe and Appl (Abebe and Appl, 1981) for cutting with a large negative rake angle, however, includes a raised prow of material joining the uncut work surface to the chip and suggests the moving wave concept during cutting. It has long been known that the intersection of the chip and the uncut surface is not a sharp corner but rather a curved surface (see, for example [Palmer and Yeo, 1963]), but it is frequently approximated to be sharp. The raised prow is therefore realistic and matches the moving wave result of the sliding wedge model. The model in (Abebe and Appl, 1981) also includes a stable build-up region as Kita (1982) observed for cutting with negative rake angles simulating grinding.

The proposed slip-line field for ploughing is shown in Figure 3 for a tool of edge radius $r_{e}$ and rake angle a equal to zero. The field resembles one developed by Shi and Ramalingam (Shi and Ramalingam, 1991) for cutting with a flank wear land. Heavy arrows in the figure show the flow of material (starting with the workpiece velocity $\mathrm{V}$ ) both into the chip and below the edge. Because of a velocity discontinuity along the lower boundary of the field, the workpiece material is seen to raise up before reaching the edge as is consistent with the wave model for sliding described above. The stable build-up region is shown shaded with point $\mathbf{A}$ at the point of material separation. AB is a type I slip-line and essentially represents the traditional shear plane inclined at the shear angle $\mathrm{f}$. The prow is shown inclined at an angle $r$ with respect to the uncut workpiece surface. The vertical distance between the uncut workpiece surface and the machined workpiece surface is the uncut chip thickness $t_{C}$.

The remainder of the field below $\mathrm{AB}$ can be determined from frictional and geometric considerations. Due to the high normal stress on the lower interface between the tool (build-up region) and the work CA, a constant frictional stress $\tau$ is assumed proportional to the material shear flow stress $\mathrm{k}$

$$
\tau=\mathrm{m} \cdot \mathrm{k}
$$

where $\mathrm{m}$ is the friction factor and $\mathrm{k}$ is related to the uniaxial yield stress $\mathrm{Y}$ through the von Mises yield criterion

$$
\mathrm{k}=\frac{\mathrm{Y}}{\sqrt{3}} .
$$

According to the governing rules of slip-line field theory (Dewhurst and Collins, 1973), slip-lines meet the bottom surface of the built-up region at angles $\eta$ and $\pi / 2-\eta$ according to

$$
\eta=0.5 \cdot \cos ^{-1}(\mathrm{~m})
$$

The fan field angles $\theta$ and $\gamma$ are found from geometrical considerations to be

$$
\theta=\frac{\pi}{4}-\rho-\phi
$$

and

$$
\gamma=\eta+\phi-\sin ^{-1}(\sqrt{2} \cdot \sin (\rho) \cdot \sin (\eta))
$$

$\mathrm{R}$ is the radius of the circular fan field centered at $\mathrm{A}$, which is solved for using the following equation 


$$
\mathrm{R}=\sqrt{\left(\begin{array}{l}
\left.\mathrm{r}_{\mathrm{e}} \cdot \tan \left(\frac{\pi}{4}+\frac{\alpha}{2}\right)+\frac{\sqrt{2} \cdot \mathrm{R} \cdot \sin (\rho)}{\tan \left(\frac{\pi}{2}+\alpha\right)}\right)^{2} \\
+2 \cdot[\mathrm{R} \cdot \sin (\rho)]^{2}
\end{array}\right.}
$$

The shear angle $\phi$ is found from measurements of the cut chip thickness $t$ according to

$$
\tan (\phi)=\frac{\frac{t_{c}}{t} \cdot \cos (\alpha)}{1-\frac{t_{c}}{t} \cdot \sin (\alpha)}
$$

where $\alpha$ is the rake angle. Strictly speaking, Equation (7) only holds for a prow angle $r$ eqaul to zero but is also a good approximation for the small values of $r$ used in this study. The portion of the field above $\mathbf{A B}$ is an approximation but does not directly affect the ploughing forces. It is shown for completeness and is similar to fields described in (Kudo, 1965).

The shearing forces are determined from the forces on the shear plane $\mathbf{A B}$, while the ploughing forces act on the bottom of the build-up region, i.e., surface CA. The stresses in the field are determined from equilibrium conditions which require

$$
\mathrm{p}+2 \cdot \mathrm{k} \cdot \varphi=\text { cons tan } \mathrm{t}
$$

along a type I ine (such as $\mathrm{AB}$ ) and

$$
\mathrm{p}-2 \cdot \mathrm{k} \cdot \varphi=\text { cons tan } \mathrm{t}
$$

along a type II ine (perpendicular to $\mathbf{A B}$ ). p is the hydrostatic stress component (positive in compression) which in plane strain is related to the principal stresses acting in the plane of deformation according to

$$
\mathrm{p}=-\frac{1}{2} \cdot\left(\sigma_{1}+\sigma_{2}\right)
$$

$\varphi$ is the angle (positive counter-clockwise) through which the slip-line has rotated. Since no normal or tangential stresses act on the free surface of the prow, $\mathrm{p}$ is equal to $\mathrm{k}$ on that surface (as well as on the dashed line in the chip - see Figure 3). On the shear plane, the sliplines have rotated by $-\theta$, resulting in (by Equation (8))

$$
\mathrm{p}=\mathrm{k} \cdot(1+2 \cdot \theta)
$$

At CA the slip-lines have rotated by $-(\theta+\gamma)$ giving

$$
\mathrm{p}=\mathrm{k} \cdot(1+2 \cdot \theta+2 \cdot \gamma)
$$

The shearing forces in the cutting (parallel to V) and thrust (normal to $\mathrm{V}$ ) directions are determined from the shear angle $\phi$ and Equation (11) $\sin (\eta)$

$$
\begin{aligned}
& \mathrm{S}_{\mathrm{cut}}=\mathrm{k} \cdot \mathrm{w} \cdot[\cos (\phi)+(1+2 \cdot \theta) \cdot \sin (\phi)] \cdot \mathbf{A B} \\
& \mathrm{S}_{\mathrm{thr}}=\mathrm{k} \cdot \mathrm{w} \cdot[(1+2 \cdot \theta) \cdot \cos (\phi)-\sin (\phi)] \cdot \mathbf{A B}
\end{aligned}
$$

where w is the width of cut and $\mathbf{A B}$ is the shear plane length,

$$
\mathbf{A B}=\frac{\mathrm{t}}{\cos (\phi-\alpha)},\left(=\frac{\mathrm{t}_{\mathrm{c}}}{\sin (\phi)} \text { for } \rho=0\right)
$$

The stresses acting normal and tangential to CA are determined from Equation (12) and the angle $\eta$ between the slip-lines and the build-up surface

$$
\begin{aligned}
& \sigma=\mathrm{k} \cdot(1+2 \cdot \theta+2 \cdot \gamma)+\mathrm{k} \cdot \sin (2 \cdot \eta) \\
& \tau=\mathrm{k} \cdot \cos (2 \cdot \eta)
\end{aligned}
$$

Ploughing forces are determined from Equation (15) and the angle between $\mathrm{V}$ and $\mathbf{C A}$, which is equal to $(\phi-\gamma+\eta)$,

$$
\begin{aligned}
& \mathrm{P}_{\mathrm{cut}}=\mathrm{k} \cdot \mathrm{w} \cdot\left[\begin{array}{l}
\cos (2 \cdot \eta) \cdot \cos (\phi-\gamma+\eta)+ \\
(1+2 \cdot \theta+2 \cdot \gamma+\sin (2 \cdot \eta)) \cdot \sin (\phi-\gamma+\eta)
\end{array}\right] \cdot \mathbf{C A} \\
& \mathrm{P}_{\mathrm{thr}}=\mathrm{k} \cdot \mathrm{w} \cdot\left[\begin{array}{l}
(1+2 \cdot \theta+2 \cdot \gamma+\sin (2 \cdot \eta)) \cdot \cos (\phi-\gamma+\eta) \\
-\cos (2 \cdot \eta) \cdot \sin (\phi-\gamma+\eta)
\end{array}\right] \cdot \mathbf{C A}
\end{aligned}
$$

where

$$
\mathbf{C A}=\frac{\mathrm{R}}{\sin (\eta)}
$$

\section{EXPERIMENTATION}

A series of orthogonal turning experiments on hollow tube workpieces of 6061-T6 aluminum were performed to evaluate the predicted forces based on the proposed slip-line field. In order to clearly see the magnitude of the ploughing forces, many of the tests were run with large edges having radii of .794 $\mathrm{mm}$ and $.397 \mathrm{~mm}$ (i.e., standard inserts rotated $90 \square$ in the toolholder so that the tool nose was used as the cutting edge). Tests with a regular (small) edge were used to ensure that the results are relevant to cutting with small edge radii. Cutting conditions for both sets of tests are presented in Table 1. Kennametal KC850 coated carbide inserts were used for all the tests. The small edges were traced by Kennametal to obtain the actual edge radius on each. The cutting speed was a constant $300 \mathrm{~m} / \mathrm{min}$ - well above the range typically associated with a large, unstable built-up edge (such as those described in (Heginbotham and Gogia, 1961). The nominal rake angle was kept at $0 \square$ - though a video camera was used 
to determine the actual rake angle when the feedrate was less than the edge radius. In the tests with large edge radii (described in detail in (Waldorf et al., 1996) some sidespread occurred in both the chip and the workpiece sublayer resulting in a trapezoidal chip cross-section and a side burr (see Figure 4). For feedrates larger than those reported in this study, the width of cut was too small to prevent considerable sidepread, and the results were judged to be invalid due to severe violation of plane strain conditions. Practical considerations in the machining setup limited the use of larger widths. In the small edge tests, very little sidespread was observed as chip widths remained within about $10 \%$ of the original width of cut. As expected, the deviation from plane strain conditions (i.e., sidespread of the chip and sublayer) decreased as the ratio of edge radius to workpiece width was reduced. Machining forces were measured using a Kistler 9257A

3-component force dynamometer connected to a digital input board on a personal computer. Some instability was observed in the small edge tests for very small feeds.

\section{RESULTS AND DISCUSSION}

\section{Shear Force Model and Shear Flow Stress Computation}

In order to evaluate the predicted contributions of ploughing in the proposed slip-line model, the shearing force model (i.e., forces acting on plane $\mathrm{AB}$ in Figure 3) must be accepted and a reasonable estimate of the shear flow stress $\mathrm{k}$ determined. The shearing forces are predicted by Equation (13) which is equivalent to the model developed by Oxley (1989) for cutting with a non-strain-hardening material, or, approximately, one in which the flow stress is constant in the deformation zone. Though the aluminum strain-hardens, an equivalent constant flow stress is assumed in the deformation zone as a first approximation.

Since very high strains, strain-rates, and temperatures are typically found in machining, k must be estimated from actual cutting tests. Because the model predicts increasing shearing forces as the uncut chip thickness is increased as compared to relatively constant ploughing forces, the ploughing component is expected to diminish in relative magnitude as the feedrate is increased. Tests with a relatively large feedrate $(.20-.24 \mathrm{~mm} / \mathrm{rev})$ and small edge radius $(.015-.035$ $\mathrm{mm}$ ) were run and the results used to obtain an estimate of $\mathrm{k}$ in the standard way (i.e., ploughing forces and prow were neglected), based on Equations (13) and (14),

$$
\mathrm{k}=\frac{\mathrm{F}_{\mathrm{cut}} \cdot \cos (\phi)-\mathrm{F}_{\mathrm{thr}} \cdot \sin (\phi)}{\overline{\mathbf{w}} \cdot \mathbf{A B}}
$$

These equations use measurements of the cut chip thickness $t$ (obtaining $\phi$ from Eq. (7)) and the total measured forces, $F_{\text {cut }}$ and $\mathrm{F}_{\text {thr. }} . \overline{\mathbf{W}}$ is the average of the cut and uncut chip widths. A value of $\underline{\mathrm{k}}$ $=226.5 \mathrm{~N} / \mathrm{mm}^{2}$ was determined, which matches well to published results from Black (1979). $\mathrm{k}$ has been found (Shaw and Finnie, 1955) to remain fairly constant over different speeds and feeds during machining, and the value was assumed to be constant for the current analysis.

So although the direct measurement of the shearing force components in the large edge radius tests was found to be impractical, an accepted model was used to estimate them in the present study. Independent verification of the model using isolated measurements of both shearing and ploughing components has been left to future research.

\section{Accommodating Material Sidespread into the Model}

As stated earlier, considerable sidepread of the chip and workpiece sublayer occurred during the large edge radius tests. To account for it, a modification to the straightforward application of the slip-line field and Equations (13) and (16) has been developed. The procedure assumes that the full uncut chip thickness (equal to the feedrate in orthogonal cutting) is encountered by the tool in the center portion of the cut, but that the uncut chip thickness diminishes linearly to zero towards each side. This assumption is based on observations of the cut chip which was found to be shaped in exactly this fashion. Figure 4 shows a typical cross-section view of a cut, in which the cut chip width $\mathrm{w}_{\mathrm{C}}$ is larger than the original workpiece width $\mathrm{w}$ (varied between $10 \%$ to $35 \%$ larger) while the center portion of the chip unaffected by sidespread - is smaller than w (varied from between $25 \%$ and $70 \%$ of the original width). Heavy arrows show the direction of tool and material flow.

As a result of such a model, the shearing forces predicted by Equation (13) are only assumed over the width of the center section determined experimentally from measurements of the machined chip dimensions. The shearing forces are then approximated to decrease linearly to zero towards the outer edges of the chip, following the profile of the chip cross-section. The ploughing forces predicted by Equation (16) primarily depend not on the chip thickness but on the size of the build-up region, which varies as the rake angle a varies (see Equation (6)). Since the entire width of the chip leaves the cutting region at the same rake angle, the ploughing forces are assumed to act over the whole width of contact $\mathrm{w}_{\mathrm{C}}$. The normal (thrust) component of ploughing, however, must decrease to zero at the edge of contact, so that the width used in Equation (16) is the original workpiece width w. The tangential (cutting) component of ploughing is due to adhesive friction (independent of normal load) and acts over the entire contact region $\mathrm{w}_{\mathrm{C}}$.

\section{Force Prediction Results - Big Edge Tests}

Results are shown in Figures 5 and 6 for the cutting tests using large cutting edge radii. In each figure the solid lines represent the average forces measured by the dynamometer and the predicted forces based on the slip line field described above. A friction factor of $\mathrm{m}=$ 0.99 was found to match well to experimentally determined values and was used in the model. It is a reasonable value because the shear stress should approach the value of the flow stress (i.e., $m=1.0$ ) for the contact between work material and build-up material. The prow angle $r$ must also be specified, and a value of $0 \square$ (i.e., no raised prow) was used for the predictions in Figures 5 and 6.

For comparison, force predictions were also made by neglecting ploughing and using Equation (13). These predictions, based only on the shearing mechanism, are shown by the dashed lines in the figures. The edge radius in Figure 5 is $\mathrm{r}_{\mathrm{e}}=.794 \mathrm{~mm}$ and it can be seen that approximately $30-50 \%$ of the cutting force and $60-70 \%$ of the thrust force is due to ploughing for values of the feedrate less than the edge radius. The slip-line model does an excellent job of accounting for the additional forces due to ploughing. Figure 6 gives the results for $\mathrm{r}_{\mathrm{e}}=$ $.397 \mathrm{~mm}$. Again, ploughing is seen to make up a large fraction of the total force, comprising $15-40 \%$ of the cutting force and $50-65 \%$ of the thrust force - somewhat less than for the $\mathrm{r}_{\mathrm{e}}=.794 \mathrm{~mm}$ case. The 
absolute magnitudes of the ploughing components are also smaller, as expected, reaching about half the magnitudes estimated for $\mathrm{r}_{\mathrm{e}}=.794$ mm. Again, predictions of the ploughing components are very accurate. Not only are the ploughing components modeled, but the chip and sublayer sidespread appear to be approximated reasonably though minor trends in the thrust force predictions (slight overprediction for small feeds, underprediction for larger feeds) are likely due to the increasing amount of sidespread observed for larger values of the ratio of feed to edge radius.

A note can be made from these results with regards to the hypothesis that ploughing forces can be computed by extrapolating the force vs. feedrate curves to zero feed (see, for example Abrecht [1960]). While Figures 5 and 6 seem to show that the force curves intercept zero feed at approximately the "steady-state" level of the ploughing forces, such an interpretation is merely speculative. The highly non-linear nature of the curves at very small feeds (due to a decreasing shear angle) complicates both the interpretation and the practical estimation of the "zero-feed" forces.

\section{Force Prediction Results - Regular Edge Tests}

Although the model is shown to perform well in simulating ploughing for a large edge radius, practical interest in machining research rests primarily with estimating ploughing for the small edges typically used in production. Figure 7 presents results for machining with a standard honed edge radius of approximately .015 to $.04 \mathrm{~mm}$ (though different insert types, particularly uncoated edges, can have significantly smaller edge radii). Forces in the figure are normalized by the width of cut since different widths were used for different tests. Although estimates of the components due to shearing are not shown in the figures, ploughing contributes significantly to the total force for feedrates on the order of the edge radius, making up about $15-25 \%$ of the cutting force and $20-40 \%$ of the thrust force according to the model predictions. Ploughing force magnitudes are a small fraction of those in the big edge tests - roughly proportional to the reduction in edge radius. As the feedrate climbs to three or four times the value of the edge radius, the ploughing component becomes very small compared to the shearing components and little difference is seen between the model predictions and those made by neglecting ploughing. Indeed, the ploughing components estimated for a feedrate of $0.2 \mathrm{mmpr}$ (neglected in the flow stress calculation of Equation (18)) were found to be small, and, if subtracted from the measured forces, resulted in a re-computed flow stress which varied by approximately $5 \%$ from the initial value.

Figure 7 shows that the total forces can be predicted accurately, but that a varying prow angle $r$ complicates the model. The cutting force predictions match the observed values well for a range of prow angles (though only angles around $0 \square$ to $5 \square$ are appropriate for the largest feedrate), but the thrust force predictions require a more accurate estimate of $r$. The largest feed is again best represented by a $0 \square$ to $5 \square$ angle, but smaller feeds correspond to larger values of r. In fact, the appropriate prow angle seems to increase as the feedrate becomes smaller. Such a relationship can be explained by considering that a greater build-up of material in the prow is experienced as the ratio of feed to width of cut decreases (i.e., the plane strain approximation improves).

Although the slip-line model does a good job of accounting for the ploughing forces during cutting, limitations in the approach leave open several areas for improvement in future research. First, a better understanding of the raised prow is needed, including a method for estimating the prow angle or determining just how the angle varies as a function of edge radius, width, etc. Second, because the plastic zone of the slip-line field ends at the bottom point on the edge, the model does not explain the effect of clearance angle on the ploughing forces. Clearance angle is thought to have an effect on cutting forces and has been shown (Sisson and Kegg, 1969) to affect process damping in dynamic cutting. A study of elastic effects and/or an extension of the slip-line field to the clearance face may be required to explain some of these observations. Lastly, experimental difficulties due to instability, machine drive precision, and measurement of the chip dimensions and rake angle remain in the practical estimation of force components under the conditions used in this study and cause uncertainty, especially for the very small feeds. Nevertheless, the model shows great promise for predicting ploughing forces as well as force components due to contact on a wear land, which may be thought of as an extension of the lower surface of the built-up region. On a worn tool, the additional generated forces can be quite significant even for cutting with a large feedrate. Therefore, further validation of the approach may involve predictions for worn tool forces.

\section{SUMMARY AND CONCLUSIONS}

A slip-line field has been developed to estimate the forces during orthogonal cutting due to ploughing by the finite radius of a honed cutting edge. The model is based on slip-line fields developed for the sliding of a rigid wedge on a deforming half-space and for orthogonal cutting at large negative rake angles. The geometry of the field includes a raised prow or ridge formed just ahead of the cut and a stable build-up of workpiece material adhered to the cutting edge which acts to divert the oncoming flow either into the chip or into the workpiece. Simulations of the model, along with results of cutting tests on 6061-T6 aluminum, allow the following conclusions to be drawn:

1) The proposed slip-line field yields excellent predictions of the total force when ploughing makes up a large proportion of the total forces, i.e., for cutting with large edge radii and small uncut chip thicknesses.

2) Good predictions are also seen for regular machining with a small cutting edge radius.

3) A relationship was observed between prow angle and the degree to which the cutting conditions approximated a plane strain process. For the tests with large edge radii a model with no prow worked well to predict forces, but a larger prow angle was needed to explain forces when a small edge was used for the cut.

The model helps to explain the size effect in metal cutting and serves as a starting point for a better understanding and prediction of the effects of tool wear and dynamic cutting. Future research will address these points, while attempting to improve on the existing model for ploughing.

\section{ACKNOWLEDGMENTS}

This work was supported in part by the NSF Industry/University Cooperative Research Center for Machine Tool Systems at the University of Illinois.

\section{REFERENCES}


Albrecht, P., "New Developments in the Theory of the MetalCutting Process, Part 1. The Ploughing Process in Metal Cutting," Trans. ASME, J. of Engineering for Industry, Nov. 1960, pp. 348-357.

Palmer, W.B. and R.C.K. Yeo, "Metal Flow Near the Tool Point during Orthogonal Cutting with a Blunt Tool," Proc. 4th Int. MTDR Conf., 1963, pp. 61-71.

Johnson, W., "Cutting with Tools having a Rounded Edge: Some Theoretical Considerations," Annals of the CIRP, v. 14, 1967, pp. 315319.

Abdel Moneim, M.Es. and R.F. Scrutton, "Tool Edge Roundness and Stable Build-Up Formation in Finish Machining," Trans. ASME, J. of Engineering for Industry, Nov. 1974, pp. 1258-1267.

Heginbotham, W.B. and S.L. Gogia, "Metal Cutting and the Built-up Nose," Proc. Inst. Mech. Engrs., v. 175, no. 18, 1961, pp. 892-905.

Rubenstein, C., "The Edge Force Components in Oblique Cutting," Int J. Mach. Tools Manufact., v. 30, no. 1, 1990, pp. 141149.

Zhang, H.T., Liu, P.D., and R.S. Hu, "A Three-zone Model and Solution of Shear Angle in Orthogonal Machining," Wear, v. 143, 1991, pp. 29-43.

Sarwar, M. and P.J. Thompson, "Cutting Action of Blunt Tools," Proc. 22nd Int. MTDR Conf., 1981, pp. 295-304.

Parthimos, Dimitris and Kornel F. Ehmann, "A Model for the Stress Field Around the Shear Zone," Trans. of NAMRI/SME, v. 21, 1993, pp. 197-204.

Wu, D. William, "Application of a Comprehensive Dynamic Cutting Force Model to Orthogonal Wave-generating Processes," Int $J$. Mech. Sci., v. 30, no. 8, 1988, pp. 581-600.

Endres, W.J., DeVor, R.E., and S.G. Kapoor, "A DualMechanism Approach to the Prediction of Machining Forces, Parts 1 and 2," Trans. ASME, J. of Engineering for Industry, vol. 117, November 1995, pp. 526-541.

Elanayar V.T., Sunil and Yung C. Shin, "Modeling of Tool Forces for Worn Tools: Flank Wear Effects," Materials Issues in Machining-II and The Physics of Machining Processes-II, Proceedings of the Winter Annual Meeting of ASME and the Fall Meeting of the Minerals, Metals, and Materials Society, 1994, pp. 341-361.

Elbestawi, M.A., Ismail, F., Du, R., and B.C. Ullagaddi, "Modelling Machining Dynamics Including Damping in the ToolWorkpiece Interface," Tribological Aspects in Manufacturing, ASME WAM, PED-Vol. 54/Trib-Vol. 2, 1991, pp. 253-264.

Sisson, T.R. and R.L. Kegg, "An Explanation of Low-Speed Chatter Effects," Trans. ASME, J. of Engineering for Industry, Nov. 1969, pp. 951-958.

Albrecht, Paul, "Dynamics of the Metal-Cutting Process," Trans. ASME, J. of Engineering for Industry, Nov. 1965, pp. 429-441.

Haslam, D. and C. Rubenstein, "Surface and Sub-surface Workhardening Produced by the Planing Operation," Annals of the CIRP, v. 18, 1970, pp. 369-381.

Thomsen, E.G., Lapsley, J.T. Jr., and R.C. Grassi, "Deformation Work Absorbed by the Workpiece During Metal Cutting," Trans. ASME, May 1953, pp. 591-598.

Usui, E., Shirakashi, T., and T. Kitagawa, "Analytical Prediction of Cutting Tool Wear," Wear, v. 100, 1984, pp. 129-151.

Connolly, R. and C. Rubenstein, "The Mechanics of Continuous Chip Formation in Orthogonal Cutting," Int. J. Mach. Tool Design Res., v. 8, 1968, pp. 159-187.

Waldorf, D.J., DeVor, R.E., and S.G. Kapoor, "On the Phenomenon of a Stable Build-up on a Large Cutting Edge Radius, "
Proceedings of the ASME 1996 International Mechanical Engineering Congress and Exposition, Symposium on the Physics of Machining Processes, November 1996.

Black, A.J., Kopalinsky, E.M., and P.L.B. Oxley, "Asperity Deformation Models for Explaining the Mechanisms Involved in Metallic Sliding Friction and Wear - a Review," Proc. Inst. Mech Engrs., Part C: J. of Mech. Eng. Science, v. 207, 1993, pp. 335-207.

Challen, J.M. and P.L.B. Oxley, "An Explanation of the Different Regimes of Friction and Wear using Asperity Deformation Models," Wear, v. 53, 1979, pp. 229-243.

Avitzur, B. and Y.D. Zhu, "A Friction Model Based on the Upper-bound Approach to the Ridge and Sublayer Deformations Update," Proc. 13th NAMRC, 1985, pp. 103-109.

Abebe, Minasse and F.C. Appl, "A slip-line Solution for Negative Rake Angle Cutting," Proc. 19th NAMRC, 1981, pp. 341-348.

Kita, Y., Ido, M., and N. Kawasaki, "A Study of Metal Flow Ahead of Tool Face with Large Negative Rake Angle," Trans. ASME, J. of Engineering for Industry, v. 104, August, 1982, pp. 319-325.

Shi, T. and S. Ramalingam, "Slip-line Solution for Orthogonal Cutting with a Chip Breaker and Flank Wear," Int. J. Mech. Sci., v. 33, no. 9, 1991, pp. 689-704.

Dewhurst, P. and I.F. Collins, "A Matrix Technique for Constructing Slip-line Field Solutions to a Class of Plane Strain Plasticity Problems," Int. J. for Numerical Methods in Engineering, v. 7, 1973, pp. 357-378.

Kudo, Hideaki, "Some New Slip-line Solutions for Twodimensional Steady-state Machining," Int J. Mech Sci., v. 7, 1965, pp. 43-55.

Oxley, P.L.B., The Mechanics of Machining: An Analytical Approach to Assessing Machinability, Ellis Horwood Limited Chichester, 1989.

Black, J.T., "Flow Stress Model in Metal Cutting," Trans. ASME, J. of Engineering for Industry, v. 101, November, 1979, pp. 403-415.

Shaw, M.C. and Iain Finnie, "The Shear Stress in Metal Cutting," Trans. ASME, v. 77, 1955, p. 115.

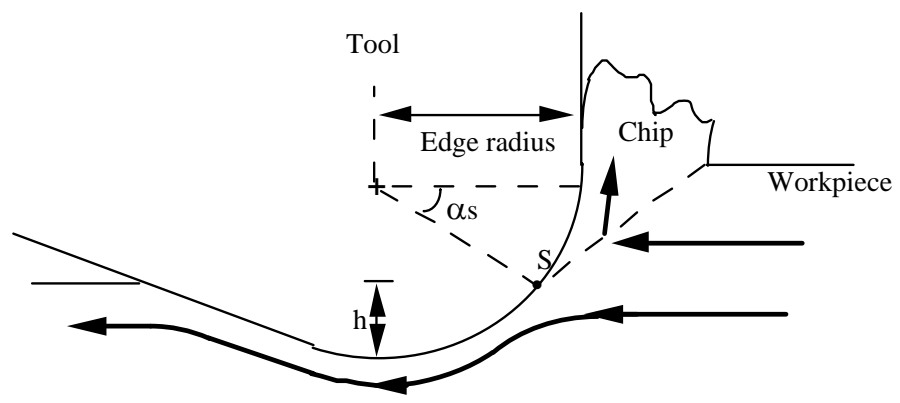

Figure 1 Extrusion-Recovery Model of Ploughing (Abebe and Appl, 1981) 


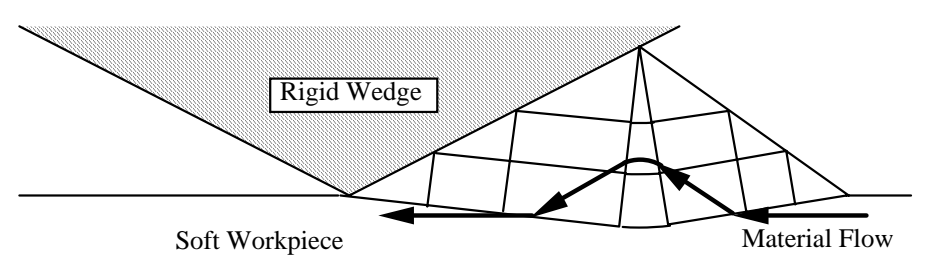

Figure 2 Slip-line Field for Sliding of a Wedge (Shaw and Finnie, 1955)

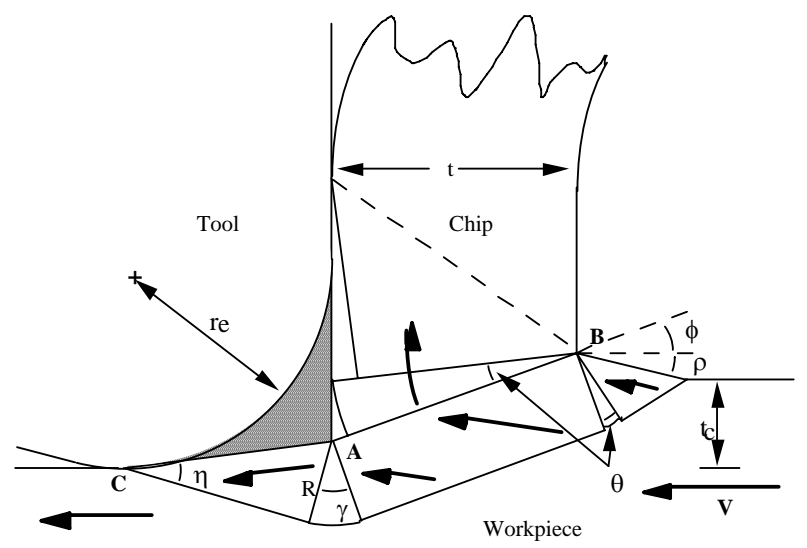

Figure 3 Proposed Slip-line Field for Ploughing

\begin{tabular}{|c|c|c|}
\hline Tests & Big Edge Tests & Small (Regular) Edge Tests \\
\hline Edge Radii & $.397, .794 \mathrm{~mm}$ & $.015-.04 \mathrm{~mm}$ \\
\hline Feedrates & $.006-.8 \mathrm{mmpr}$ & $.012-.2 \mathrm{mmpr}$ \\
\hline Cutting Speed & $300 \mathrm{~m} / \mathrm{min}$ & $300 \mathrm{~m} / \mathrm{min}$ \\
\hline Width of Cut & $2.67-3.05 \mathrm{~mm}$ & $2.98-5.56 \mathrm{~mm}$ \\
\hline Rake Angle (Nominal) & $0 \square$ & $0 \square$ \\
\hline Rake Angle (Observed) & $-36 \square-0 \square$ & $0 \square$ \\
\hline Clearance Angle & $30 \square$ & $11 \square$ \\
\hline
\end{tabular}

Table 1 Cutting Conditions for the Orthogonal Machining Tests

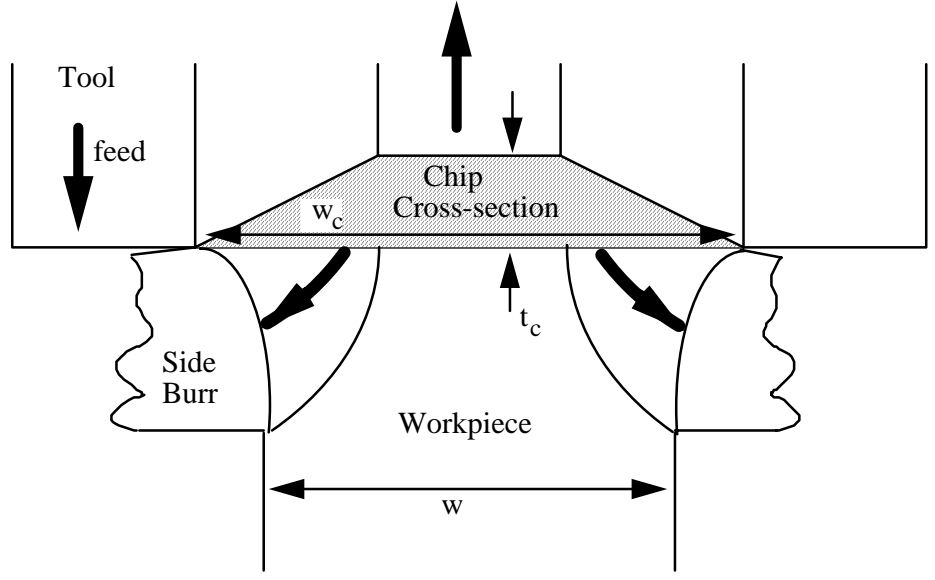

Figure 4 Cross-section View of Cut with Chip and Sublayer Sidespread

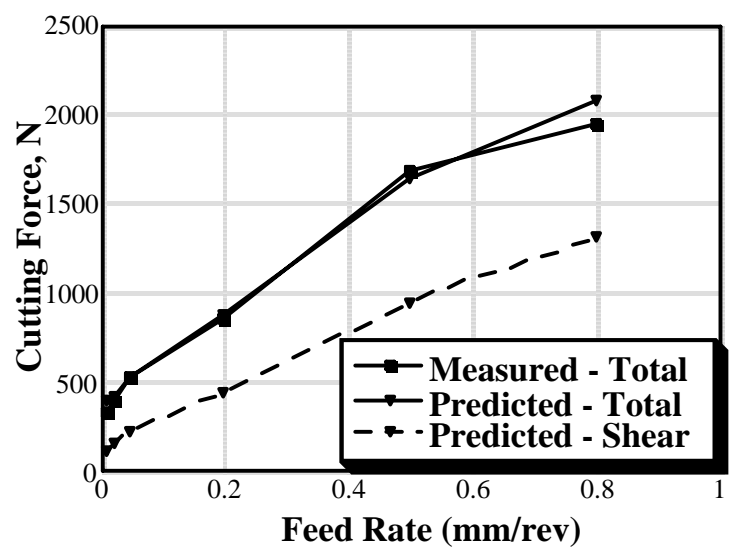

(a)

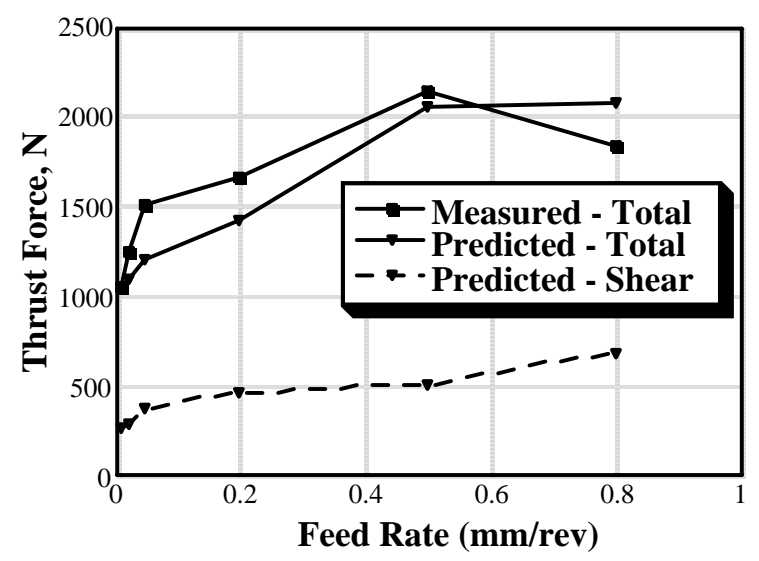

(b)

Figure 5 Measured and Predicted (a) Cutting and (b) Thrust Forces for $r_{e}=.794 \mathrm{~mm}, w=3 \mathrm{~mm}, \mathrm{v}=300 \mathrm{~m} / \mathrm{min}, \mathrm{a}=0 \square$ 


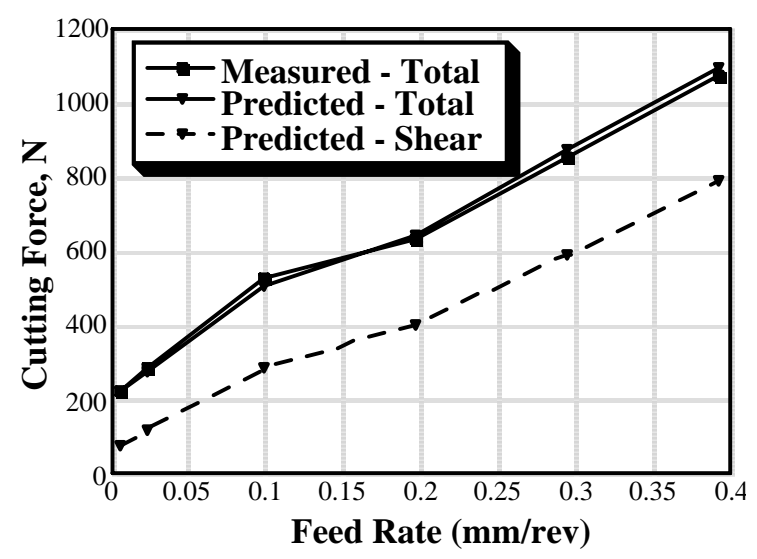

(a)

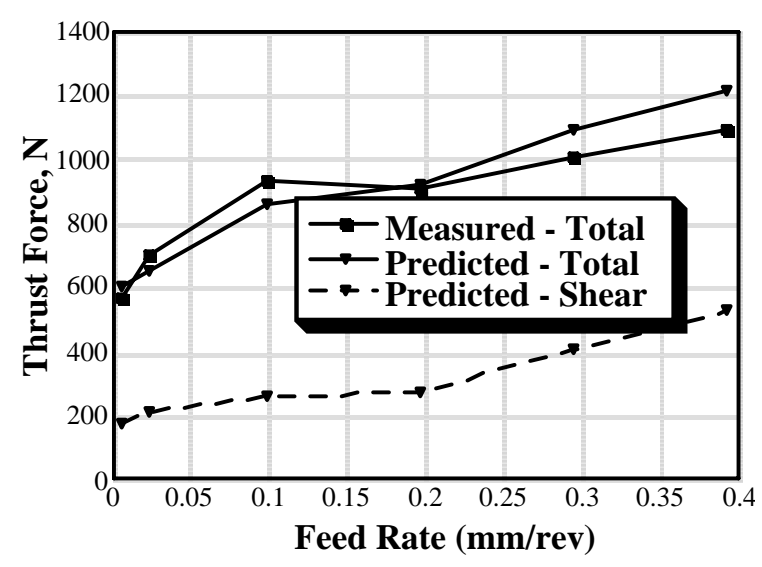

(b)

Figure 6 Measured and Predicted (a) Cutting and (b) Thrust Forces for $r_{e}=.397 \mathrm{~mm}, w=3 \mathrm{~mm}, \mathrm{~V}=300 \mathrm{~m} / \mathrm{min}, \mathrm{a}=0 \square$

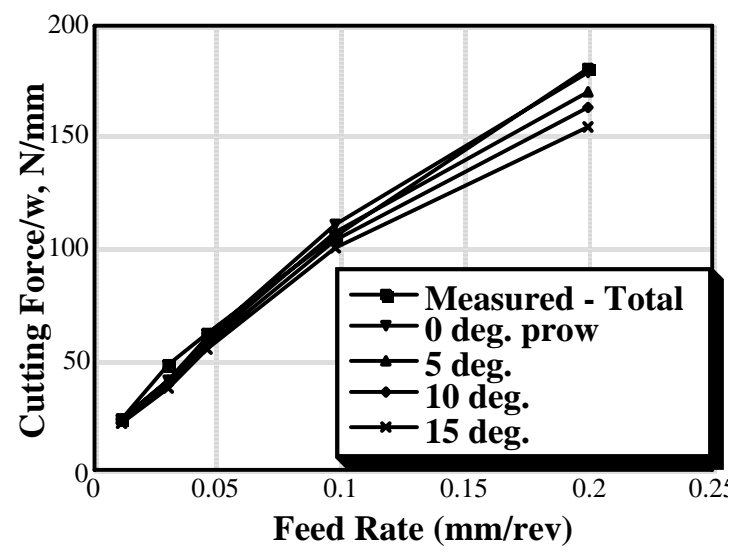

(a)

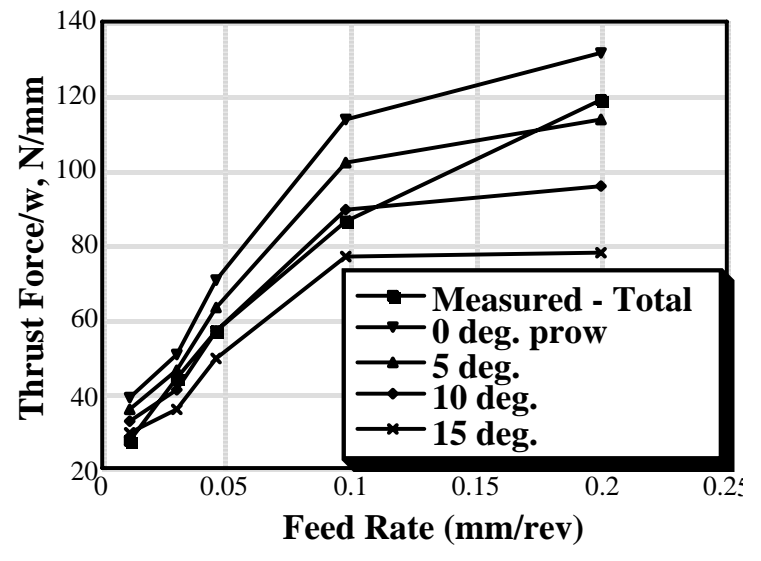

(b)

Figure 7 Measured and Predicted Normalized (a) Cutting and (b) Thrust Forces for $r_{e}=.015-.035 \mathrm{~mm}, V=300 \mathrm{~m} / \mathrm{min}$, $\alpha=0^{\circ}$, and Varying Prow Angle 